\title{
Personnel Management on the Production Line Using the FlexSim Simulation Environment
}

\author{
Marek Krynke (0000-0003-4417-1955) \\ Faculty of Management, Czestochowa University of Technology. Armii Krajowej 19 B, $42-200$ Czestochowa. \\ Poland. E-mail: marek.krynke@wz.pcz.pl
}

The article presents new possibilities of simulation software and its application to improve the production structure. In many enterprises, the basic issues are related to the determination of planned tasks for individual positions, calculating the demand for employees, taking into account their skills and qualifications, calculating work costs, determining work efficiency and its dynamics. Therefore proper work organization consists in setting the course of work in such a way as to obtain maximum results with the least amount of work by man and machine. The article presents the problem of personnel allocation to the production line. The basic stages of developing a simulation model of this process are discussed, including all necessary information and inputs. The results shows impact of the selected simulation scenarios to the workload level of the staff and the duration of the production process. In this concept, to solve the problem a simulation model of the production process was built. A new generation of 3D FlexSim simulation environment with an integrated OptQuest optimization module was used.

Keywords: Production Management, Simulation, Flexsim, Optimization, Performance Evaluation

\section{Introduction}

The current economy requirements, which include in the growing competition on a global scale, changing customer expectations or increasing the emphasis on the quality of products. It is necessary to change the thinking paradigm, and thus a new look at the issues of production management. [1-3]. The issue of dominant importance is the organization of production processes in such a way that production is based on specific customer orders is possible, in the shortest possible time, without unnecessary storage of products, production downtime, production shortages or minimizing the number and time of control and transport operations [4-7].

The main production factors are resources of work, work items and human work, and their interdependence in the production process has a decisive influence on the effectiveness and efficiency of the all production system [8]. It is especially important when using multi-station work in production, where the work of a person and the position must be adjusted in an appropriate way [9].

For human work to be effective, it should be properly organized. Proper work organization consists in setting the course of work in such a way as to obtain maximum results with the least amount of work and technical resources and the least time loss $[10,11]$. Badly organized work leads to unnecessary consumption of resources of production and human work, not bringing economic effects commensurate with the in- curred inputs, and also not contributing to the creation of optimal conditions for the working person $[12,13]$.

Production planning problems can be vary. In planning, it is necessary to determine the best organizational solutions of cooperating resources of work [14], allocate production tasks, define the needs and availability of resources [15], assess the costs of work, analyze the risks [16], etc. However, the main planning issue is to appoint a team to perform a specified scope of work in the determined or sought optimal risk [9].

The development of modern computer technology and many fields of science, especially in the field of production engineering, resulted in the emergence of the concept of a digital factory, understood as an entity representing a virtual reflection of real production processes [17]. Thanks to the use of comprehensive IT solutions in the field of modeling and simulation of manufacturing processes, a significant economic benefit is achieved, especially in mass production $[18,19]$. Hence, more and more often IT solutions appear in the area of tracking, monitoring and visualizing the course of production processes in real time [20, 21]. The effectiveness of the production planning and scheduling processes, in particular at the stage of simulating virtual models of a digital factory, depends primarily on the applied mathematical models and optimization algorithms [22]. In complex production systems, this efficiency is translated primarily into achieving a lower level of production costs, shorter production cycle times with high data processing efficiency at the same time. A short time of reaction of the digital 
model to changes introduced in it is also desirable [23].

Selected issues in this field will be the subject of considerations and proposals for planning techniques in this paper. The proposed analysis is a starting point for determining the production capacity and load for each workplace. This is especially important when using multi-station work and balancing the production line.

\section{Simulation of production systems}

During the simulation of the modeled processes, the values of parameters describing the course of the characteristic quantities of the tested process are calculated. The simulation consists in the replication of elements that occur successively over time [24, 25]. Structure of the simulation algorithm is shown in Fig. 1.

\section{Analysis of the problem} of the order of tasks

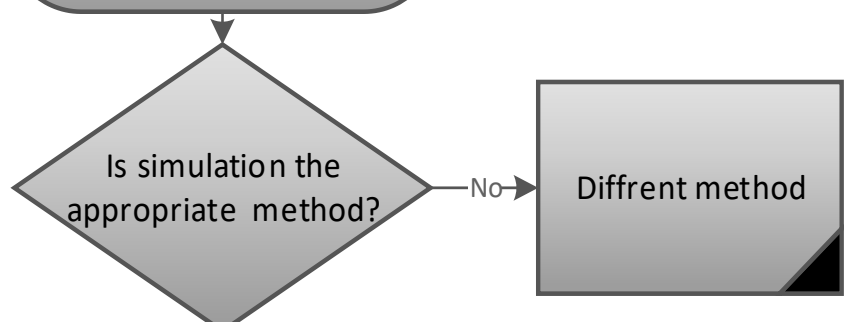

Yes

r

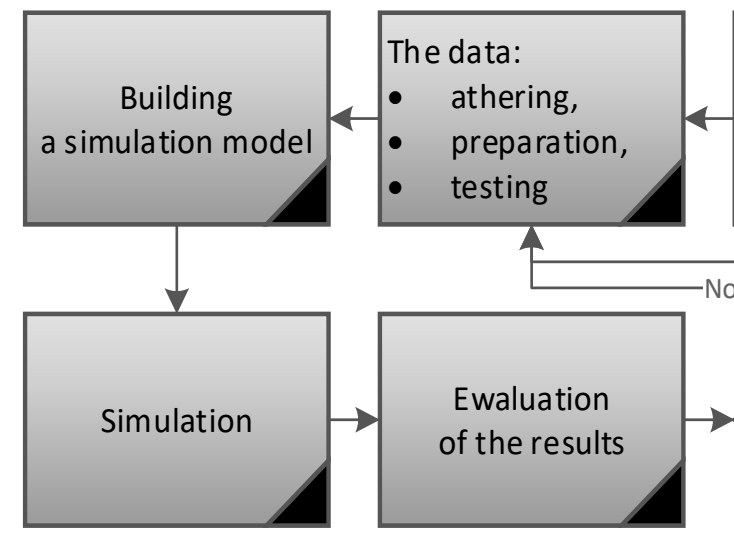

Aim of the project, the model concept, requirements, cost and time

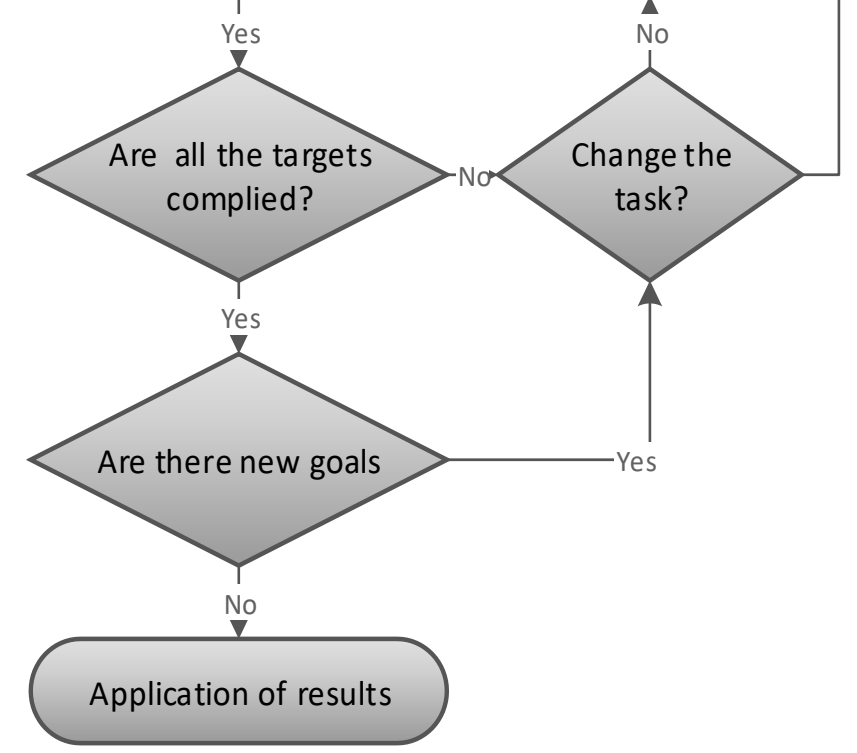

Fig. 1 Main activities in the project simulation

In computer simulation, the queuing theory is used, which allows for the analysis of the queue of elements awaiting processing, or production orders awaiting execution at a given workstation. The basic parameters of this method are: workstation service time and waiting time before processing the next 
product [26].

Computer simulation can be used to aid the effective and innovative manufacturing concepts such as Material Requirements Planning, Just In Time, Lean Production, Total Quality Management, Virtual Factory, Optimized Production Technology [27, 28]. The basic condition for the success of the project simulation is realizing it at the right time period. Very often companies use this method when the possibilities in relation to the impact on the final solution and the level of investment are already very limited [11].

FlexSim provides extensive support for the construction of simulation models, analysis and their verification. It was developed by FlexSim Software Products, Inc. FlexSim is a fully configurable, graphically oriented simulation software that integrates modeling, simulation and 3D visualization as well as animation in a three-dimensional object-oriented environment such as "drag, drop and connect" [29].

In a simulation system, a discrete or continuous flow is created using predefined modeling objects that are complete parameterized basic elements of model creation. Discrete objects (which create, send, and store elements pending execution, create product flows through the model, group and perform technological operations on products, etc.) are used to develop discrete event simulation models where the behavior of the model results from events occurring in a discrete point in time [25]. Predefined objects are available in libraries. In addition, the system offers mechanisms that allow for automatic import and export of data from external sources and mechanisms that facilitate data analysis [30].

\section{Assumptions for the construction of the si- mulation model}

The application research presented in this paper concerns the use of the Lean Manufacturing methodology and the FlexSim IT tool in order to optimize the production process in a certain enterprise. This process concerns the production of machine components. These products are manufactured at several workstations. Eight workers are employed in their production. During the simulation experiment, decisions should be made regarding the employment of the optimal number of employees so that the production time for a single batch is the shortest.

In order to obtain the results necessary to conduct the analysis, a model reflecting the considered process was built in the FlexSim simulation software. In this model, the parameters generated by the analyzed process (production duration, level of generated costs) were verified. As a result of the computer simulation, the results were obtained, enabling the selection of the optimal number of employees from among the tested variants of the organization of production (ensuring reduction of production time and costs).

At the initial stage of creating the simulation model, the assumptions concerning the considered manufacturing process were made, i.e. [31]:

- It was assumed that the production time of one element at each workstation is described by the normal distribution $N(\mu, \sigma)$, where: $\mu-$ mean value, $\sigma-$ standard deviation. The standard deviation takes into account the uneven processing due to external factors, e.g. different quality of the raw material.

- Raw materials for the production hall are delivered by a forklift.

- Transport between machines is done manually with the use of operators.

- Operators are trained at all workstations and are able to perform all technological operations at every workstation.

- The manufacturing process manager has 8 employees with the same performance at his disposal.

- Operators move at a speed of $1 \mathrm{~m} / \mathrm{s}$ on communication routes and may pass each other.

- Breakdowns, work breaks, and other disruptive factors are disregarded.

- $\quad$ P The production process consisted of making only one series of elements of the selected type.

In order to map the existing production process, sets of the following values have been set: input (type and time of material flow), output (time of making a specific batch of elements), constant (type and time of performing technological operations as well as used production stations and their arrangement).

Table 1 summarizes the data on the duration of individual technological operations, process routes and work stations on which the selected operation will be performed. The duration of technological operations presented in Table 1 covers the total duration of a given production operation (there is no division into unit time and preparatory-completion time).

Figure 2 shows the technological approach to the production process. In this process, there are 7 technological operations that bring added value to the product and one control operation. The others are storage and transport operations. 
Tab.1 List of technological operations

\begin{tabular}{|c|c|c|c|c|}
\hline $\begin{array}{l}\text { Operati- } \\
\text { on num- } \\
\text { ber }\end{array}$ & Type of operation & $\begin{array}{l}\text { Workstation, } \\
\text { type of transport }\end{array}$ & $\begin{array}{l}\text { Process time } \\
\text { [minutes] }\end{array}$ & Distance $[\mathrm{m}]$ \\
\hline 1. & Raw material storage & Queue & - & - \\
\hline 2. & Inter-departmental transport & Forklift & - & 50 \\
\hline 3. & Inter-operational storage & Queue & - & - \\
\hline 4. & Inter-workstations transport & Operator & - & 3.5 \\
\hline 5. & Cutting the material & Processor & 7.5 & - \\
\hline 6. & Inter-workstations transport & Operator & - & 3.5 \\
\hline 7. & Inter-operational storage & Queue & - & - \\
\hline 8. & Inter-workstations transport & Operator & - & 3.5 \\
\hline 9. & Drilling & Processor & 4.1 & - \\
\hline 10. & Inter-workstations transport & Operator & - & 3.5 \\
\hline 11. & Inter-operational storage & Queue & - & - \\
\hline 12. & Inter-workstations transport & Operator & - & 3.5 \\
\hline 13. & Turning & Processor & 11.0 & - \\
\hline 14. & Inter-workstations transport & Operator & - & 3.5 \\
\hline 15. & Inter-operational storage & Queue & - & - \\
\hline 16. & Inter-workstations transport & Operator & - & 3.5 \\
\hline 17. & Gear hobbing & Processor & 28.8 & - \\
\hline 18. & Inter-workstations transport & Operator & - & 3.5 \\
\hline 19. & Inter-operational storage & Queue & - & - \\
\hline 20. & Inter-workstations transport & Operator & - & 3.5 \\
\hline 21. & Gear chiselling & Processor & 21.3 & - \\
\hline 22. & Inter-workstations transport & Operator & - & 3.5 \\
\hline 23. & Inter-operational storage & Queue & - & - \\
\hline 24. & Inter-workstations transport & Operator & - & 3.5 \\
\hline 25. & The heat treatment & Processor & 10 & - \\
\hline 26. & Inter-workstations transport & Operator & - & 3.5 \\
\hline 27. & Inter-operational storage & Queue & - & - \\
\hline 28. & Inter-workstations transport & Operator & - & 3.5 \\
\hline 29. & Grinding & Processor & 7.0 & - \\
\hline 30. & Inter-workstations transport & Operator & - & 3.5 \\
\hline 31. & Inter-operational storage & Queue & - & - \\
\hline 32. & Inter-workstations transport & Operator & - & 3.5 \\
\hline 33. & Control & Processor & 5.0 & - \\
\hline 34. & Inter-workstations transport & Operator & - & 3.5 \\
\hline 35. & Completing products & Queue & - & - \\
\hline 36. & Inter-departmental transport & Forklift & - & 50 \\
\hline 37. & Finished products storage & Queue & - & - \\
\hline
\end{tabular}



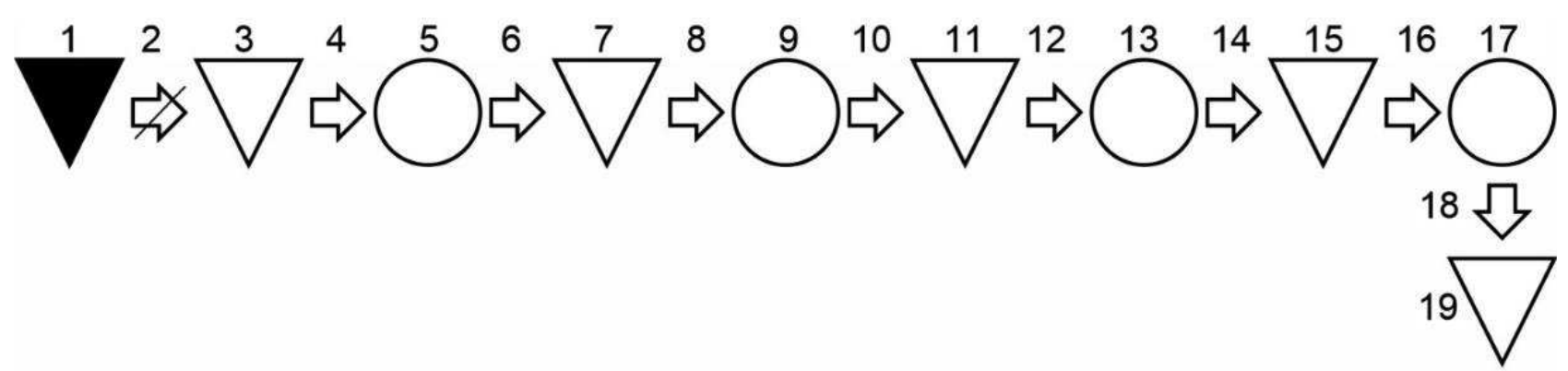

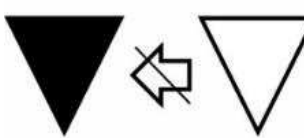

37

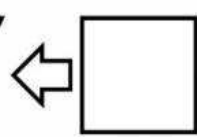

34

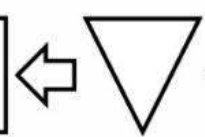

$32 \quad 31$

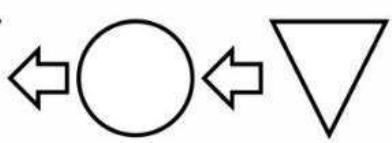

$30 \quad 29$
$28 \quad 27$

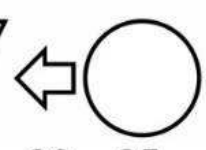

$26 \quad 25$

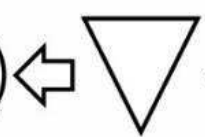

24

23

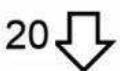

Fig. 2 Diagram of the analyzed production process

\section{Construction of a simulation model using FlexSim software}

The task of the simulation model being built was to faithfully reproduce the considered production process. Therefore, it has become necessary to correctly model the entire simulation system, along with the determination of the relationships between individual objects and assigning them to characteristic quantities. The components included in the model included: source, 8 production stations, 8 operators, 10 interoperational buffers, 1 buffer for defective products, 2 transporters and a warehouse for finished products. An important active element is the manager (dispatcher). In the simulation model, it is an element that controls the work of operators. In the analyzed case, there is only one manager who controls all the assigned employees. The exact location of machines, operators and a communication plan are shown in Fig. 3.

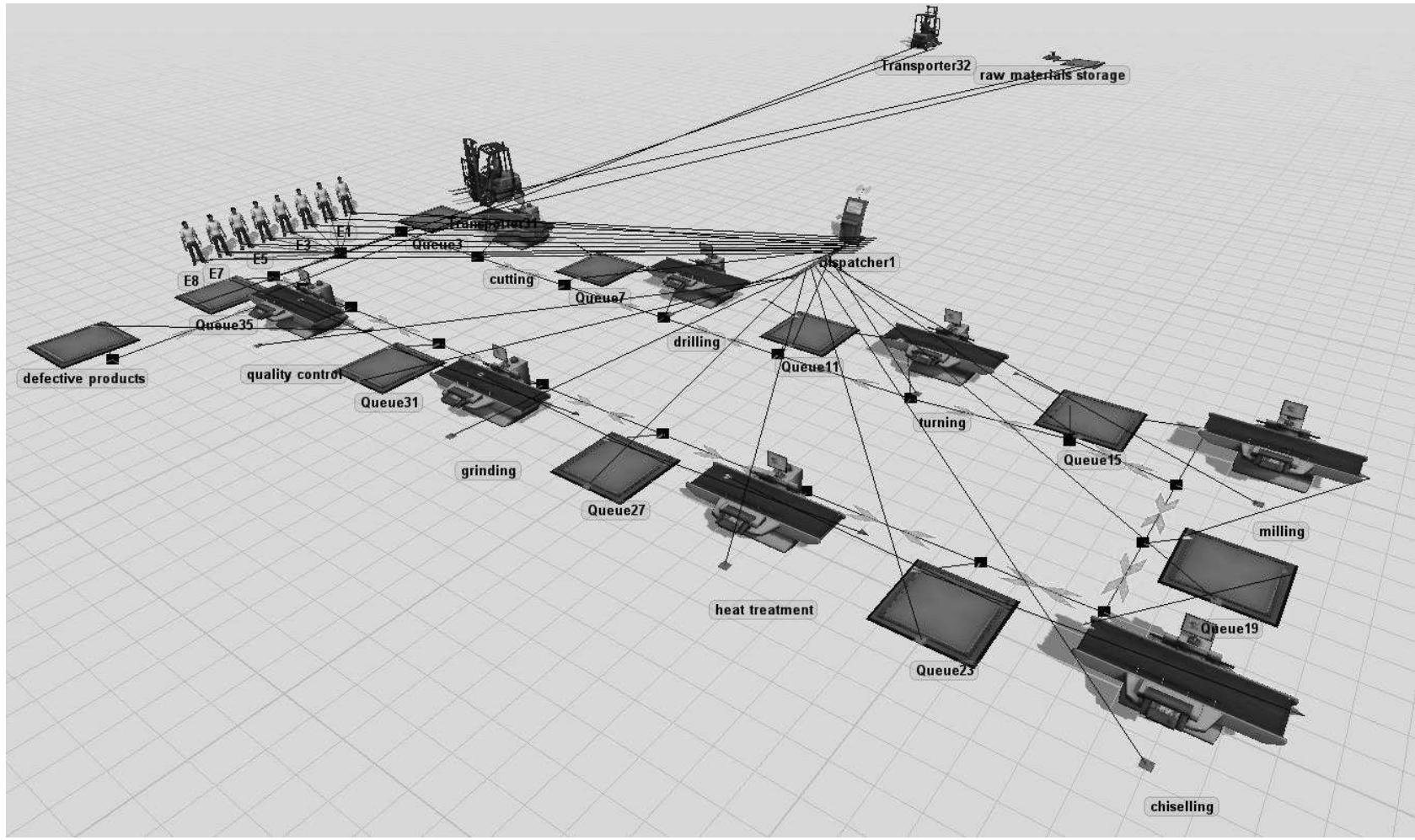

Fig. 3 Model of the analyzed production line in the FlexSim program

The quantity of products is defined directly in the material source using the Arrival Sequence command. It was established that the flow element that will be gen- erated in the model will be a box simulating the processed detail. For the purposes of the model, it was assumed that the flow elements would be generated in 
the amount corresponding to the size of the production batch. The raw materials are then transported by a forklift to the first queue at the cutting station. The maximum capacity for the queue at all stations corresponded to the size of the production batch. The flow paths along which operators move were simulated using an element - Network Nodes from the Travel Networks library. All operators are connected to the created route network. The control unit for the employees is the manager (Dispatcher). The manager is connected by a central port with all production stations. The manager also has the function of assigning employees the shortest route, if possible. In the program it is realized with the algorithm of finding the shortest path, the so-called Dijkstra's algorithm [32]. Individual workstations are simulated using the Processor object, while storage by a workstation are simulated using the Queue element. Quality control is carried out on the last station, which was designed with the use of a processor. The time spent by one flow element in the processor is 5 minutes. Based on historical data, the ratio of products meeting the quality standards to defective products was assumed in the ratio of $99 \%$ to $1 \%$ [33]. Correct products go to the queue from where they are transported by a transporter to the finished products warehouse. Products that do not meet the quality standards go to the second queue - defective products. This can be set in the processor properties by selecting "By Percentage" for the flow ports [34].

After building the simulation model and connecting all the elements, the parameters defining the duration of individual operations, the size of the production batch, the amount of the cost of a given unit and the flow of the manufactured details were defined. The amount of the labor cost of the selected production position was calculated on the basis of the analysis of departmental and general management expenses as well as theoretical costs resulting from the assumed selling price of the manufactured element and the purchase price of raw materials. In the case under consideration, the cost of work or standstill of one production station was set at a constant level of 30 monetray units per hour. Whereas the costs for all employees are equal and are 20 monetary units per hour.

In order to determine the optimal number of operators, needed perform an experiment with 8 scenarios. The individual scenarios assume the employment of 1 to 8 operators successively and measuring the production time of a batch of products, adding an additional five replications of each experiment.

If you want to experiment with multiple scenarios, you must select the number of operators that are inputted as input. It is done by the experimenter's function: Number of Task Executer [31]. In the following scenarios, an analysis of the model's performance is obtained with employment of one to eight operators respectively.

The output variable is the total execution time of the task. Custom code should be used, as the parameter such as system time from model operation is not in the drop-down list as a ready-made function. To obtain the total production time of 100 items, when employing successively from one to eight operators in accordance with the production scenarios, in the tab for the measured variable Performance Measures in the code editing window enter the function: return time () [31].

\section{Study of the optimal number of operators in the manufacturing process}

After performing five replication of each scenario, the confidence intervals of production times for a single batch of orders were obtained. Graphical interpretation in the form of charts is shown in Fig. 4.

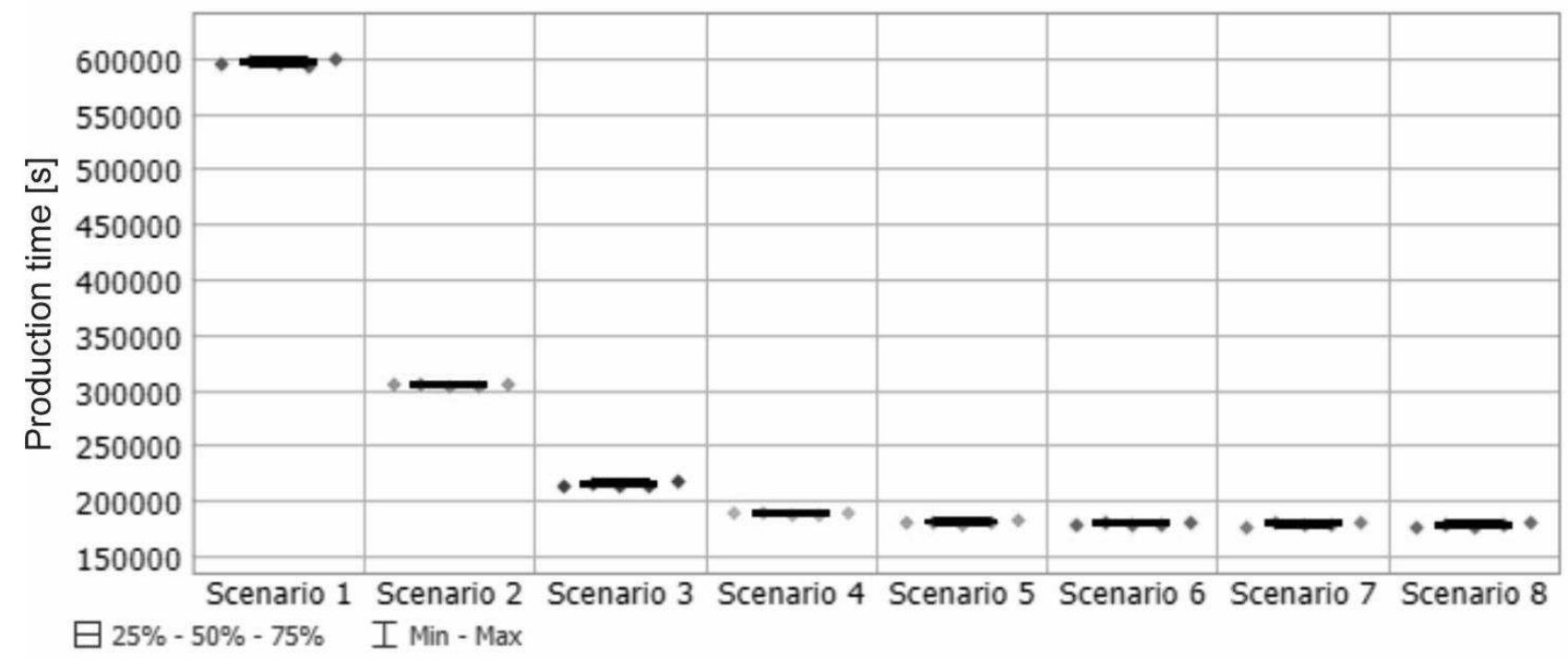

Fig. 4 Confidence intervals of production times for the tested scenarios 
The presented results were designated as the $90 \%$ confidence interval for the studied phenomenon. In practice, this means that there is a $90 \%$ probability that an unknown population paprameter (in this case the production time) will fall within the designated numerical range. The calculated confidence intervals, median, standard deviation as well as the maximum and minimum values for individual scenarios in the simulation experiment are shown in Table 2.

Tab. 2 Duration of the production process for the tested scenarios

\begin{tabular}{|l|l|l|l|l|l|c|c|c|}
\hline & \multicolumn{5}{|c|}{ Mean $(90 \%$ Confidence) [s] } & Sample Std Dev [s] & Min [s] & Max [s] \\
\hline Scenario 1 & 593948 & $<$ & 596063 & $<$ & 598179 & 2219 & 593670 & 599064 \\
\hline Scenario 2 & 304307 & $<$ & 305356 & $<$ & 306406 & 1101 & 304227 & 306825 \\
\hline Scenario 3 & 213419 & $<$ & 215091 & $<$ & 216763 & 1753 & 213648 & 217355 \\
\hline Scenario 4 & 187595 & $<$ & 188690 & $<$ & 189784 & 1148 & 187352 & 190184 \\
\hline Scenario 5 & 179853 & $<$ & 181064 & $<$ & 182274 & 1270 & 179319 & 182805 \\
\hline Scenario 6 & 178027 & $<$ & 179514 & $<$ & 181000 & 1559 & 177888 & 181570 \\
\hline Scenario 7 & 177356 & $<$ & 178981 & $<$ & 180607 & 1705 & 177433 & 181438 \\
\hline Scenario 8 & 177154 & $<$ & 178709 & $<$ & 180263 & 1630 & 176998 & 181028 \\
\hline
\end{tabular}

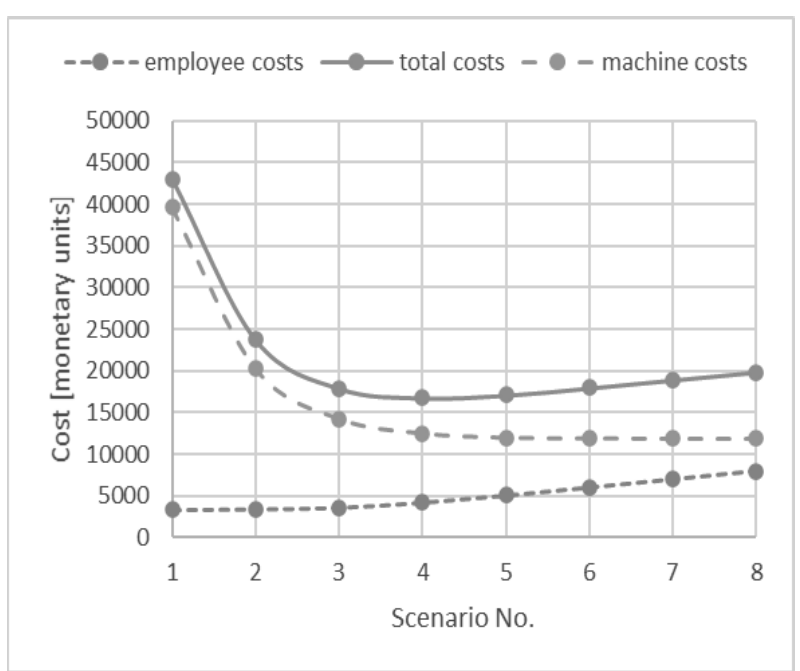

Fig. 5 Production costs for next tested scenarios

Figure 5 shows the production costs of the batch of products for next scenarios $1 \div 8$. Machine utilize costs will decrease as the number of operators increases, but only up to a certain limit. This limit is determined by the efficiency of the machines, which is independent of the operators. Therefore, with the number of operators above 4 , the costs of the machines remain constant. In turn, the costs of employees will increase for the next scenarios. This is due to the fact that with more operators, their total idle time increases, which reduces the efficiency of their work. The curve showing the total costs (Fig. 5) has its extreme for the minimum value, which is for scenario 4 , i.e. a situation where 4 operators are employed.

On the basis of the obtained results, it was concluded that Scenario No. 4 is the best, because in the system does not have more tasks to be performed simultaneously for more than 4 operators. Such tasks may occur very rarely, which does not change the fact that it is not profitable to employ more than 4 operators. It should be noted that the production time is given with an appropriate probability and is within the specified confidence interval, ie $187352 \mathrm{~s}<\mu<190184 \mathrm{~s}$.

In Figure 6, the burden on subsequent employees for scenario 4 is presented. It is worth noting that in subsequent replications of the model, different results of the utilize on individual operators are obtained. This is due to the randomness of the model, where during the simulation in subsequent replications tasks for individual operators are selected. The last graph in Figure 6 shows the composite value of the utilize from all operators. The variability of this value is much smaller (by an order of value) in next replications of the simulation.

Figure 7 shows the resultant value of the operators utilize for the 8 surveyed scenarios. In the case of the first 4 scenarios, it can be noticed, that the total value of use of all operators, is influenced by a few percent of the time spent on transporting the semi-finished products to the workstation.

With a larger number of operators, the time allocated to transport does not contribute much because the operators occupy positions at designated positions and do not have to move to other positions. The results themselves in terms of production time differ slightly for the last 4 scenarios and are very similar to each other. With 4 operators employed, the average time was 188690 seconds, i.e. the order can be processed in approximately 52.5 hours, which, taking into account the regeneration breaks, corresponds to e.g. 7 work shifts of 8 hours each. In the case of a greater number of operators, there is a significant share of the idle time of these operators in their total time allocated to the execution of assigned tasks. 
Travel empty Travel loaded O Offset travel empty $\quad$ Offset travel loaded Utilize Idle

\section{Replication 1}

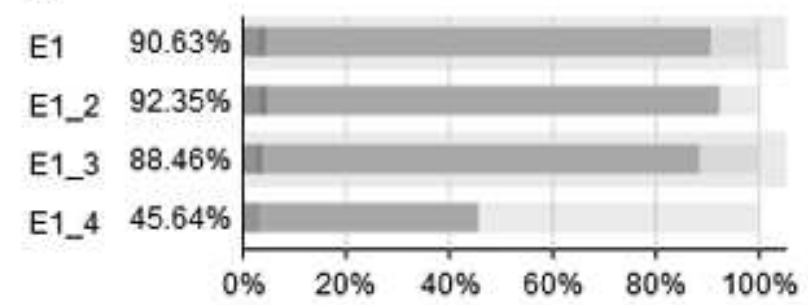

\section{Replication 3}

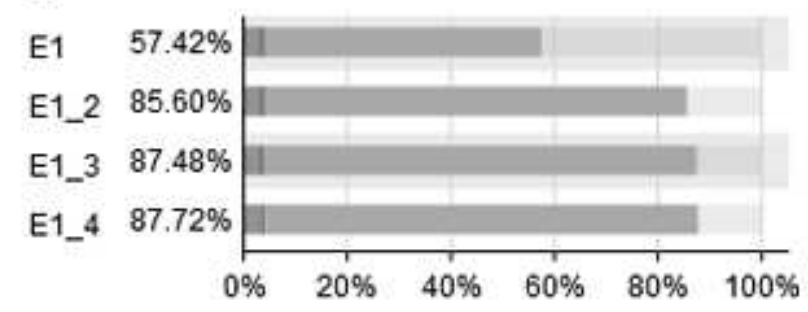

\section{Replication 5}

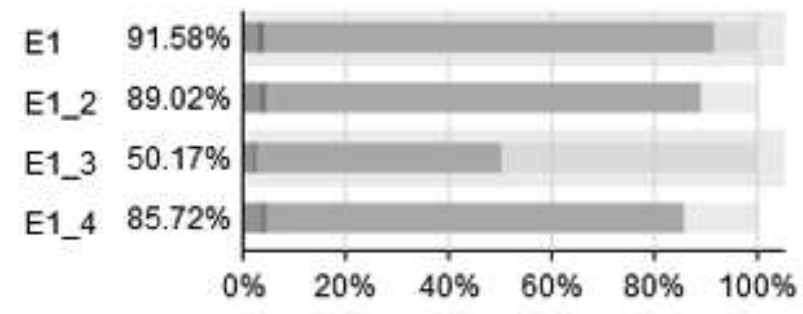

Replication 2

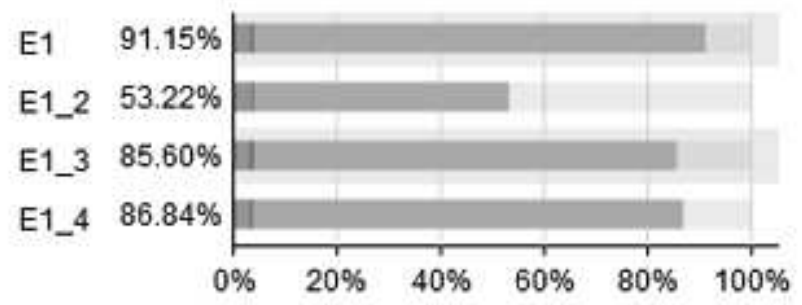

Replication 4

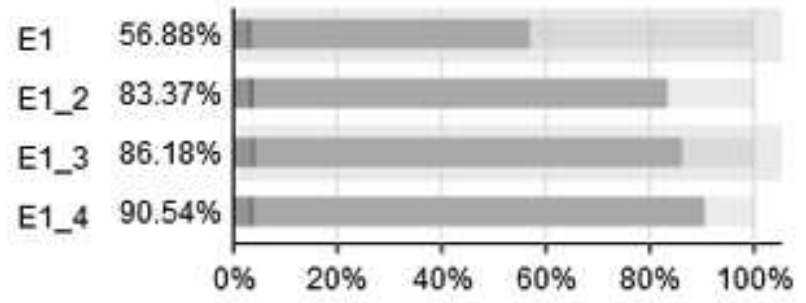

Composite from replication $1 \div 5$

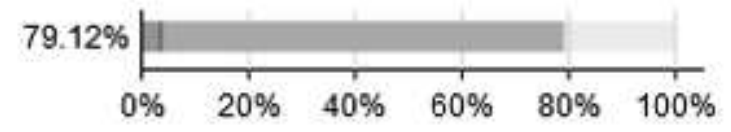

Fig. 6 The utilize of individual operators for the next 5 replications for scenario 4

Travel empty $\square$ Travel loaded $\square$ Offset travel empty $\square$ Offset travel loaded $\square$ Utilize Idle

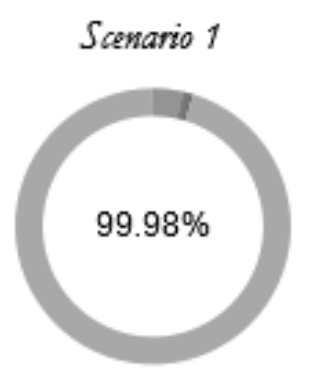

Scenario 5

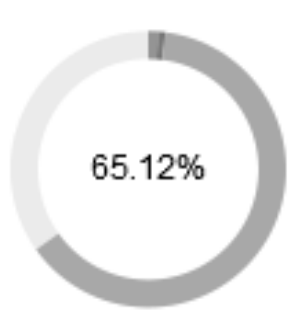

Scenario 2

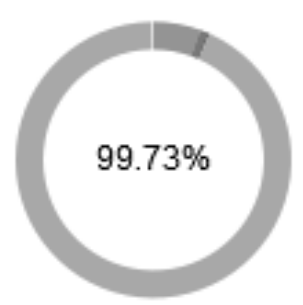

Scenario 6

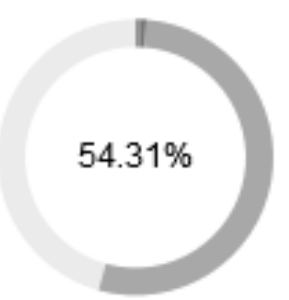

Scenario 3

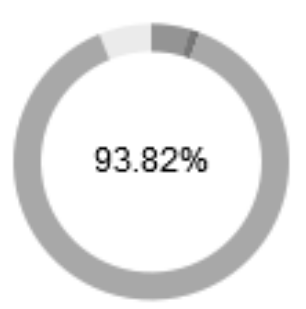

Scenario 7

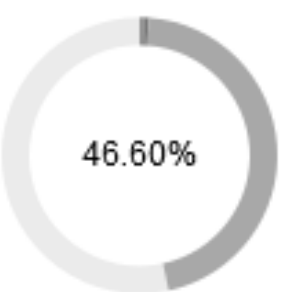

Scenario 4

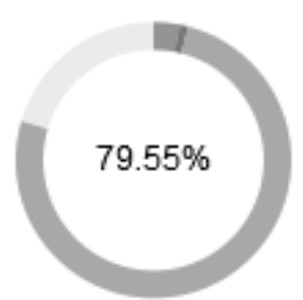

Scenario 8

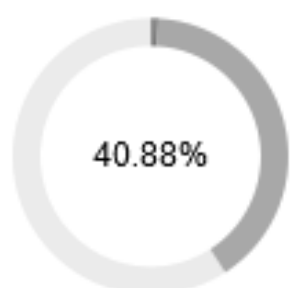

Fig. 7 Composite value of the utilize state of all operators for the tested scenarios

Figure 8 presents a graph showing the degree of utilize of individual workstations for all tested scenarios. In the case of the first 4 scenarios, there are pro- duction interruptions due to the waiting of the operator position. In the following scenarios, it can be seen that such interruptions do not occur anymore, so the 
production time will be determined only by the efficiency of individual workstations. This is a clear signal

\section{Scenario 1}

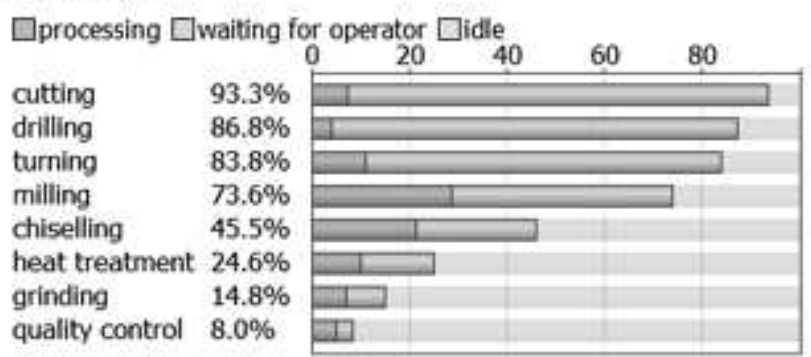

\section{Scenario 3}

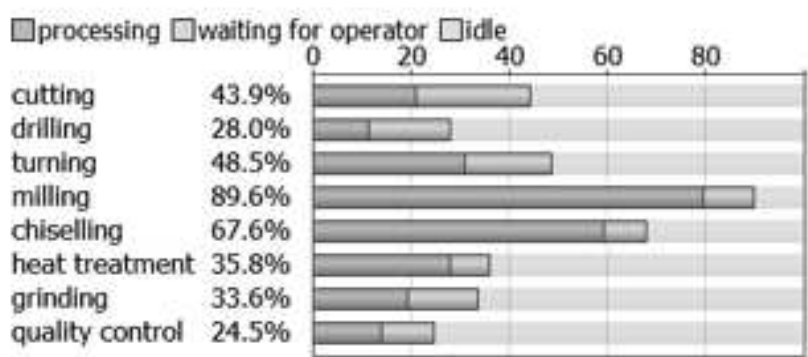

\section{Scenario 5}

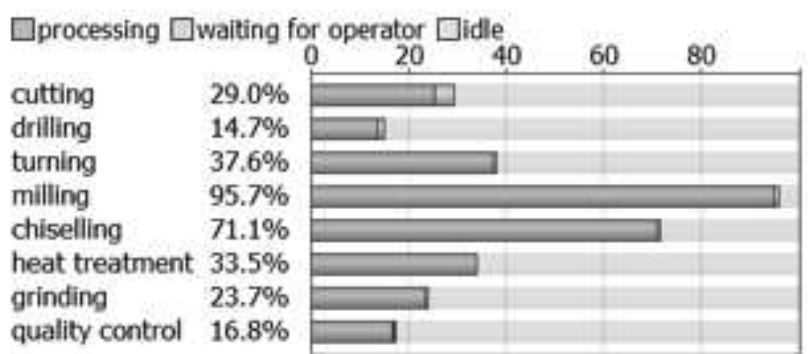

\section{Scenario 7}

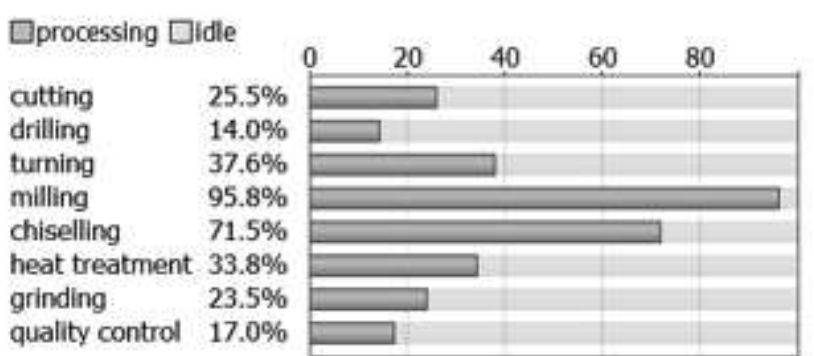

to the management that there is no justification for hiring more people in such a situation.

\section{Scenario 2}

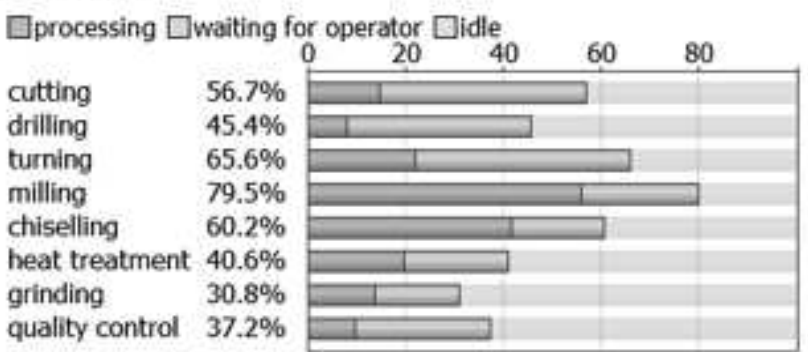

\section{Scenario 4}

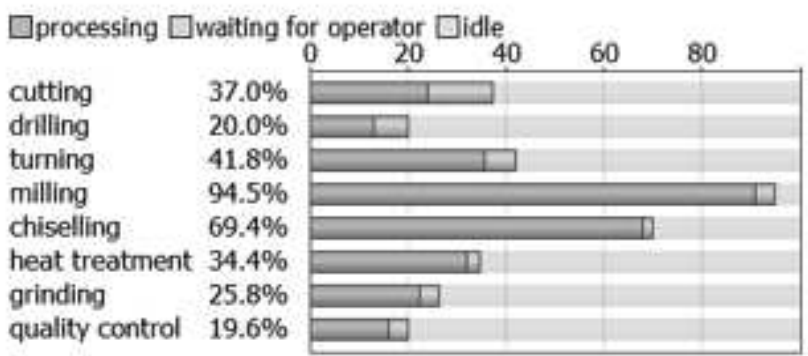

\section{Scenario 6}

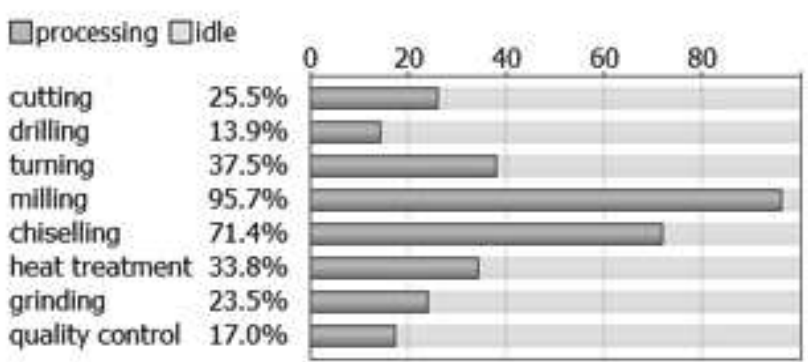

\section{Scenario 8}

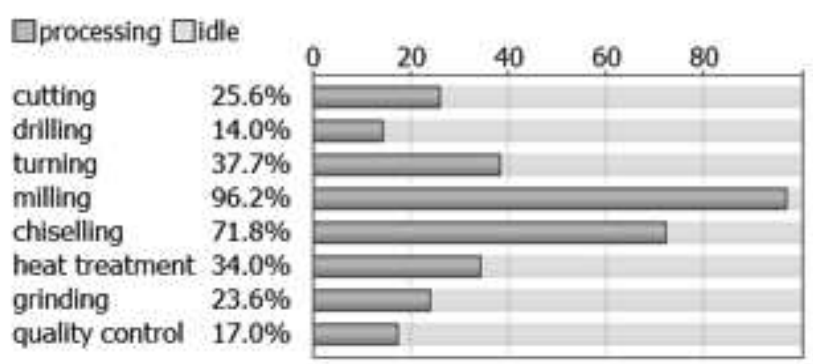

Fig. 8 The utilize on individual workstations throughout the production cycle for the 8 tested scenarios

In the case of a simulation experiment, an optimal production structure is obtained, selected from among the studied scenarios, most often proposed by the company's management. It does not mean, however, that the obtained result is the best among the entire set of permissible decisions. After all, decision makers can be wrong because they base their scenarios only on assumptions or their own knowledge, which may not always be perfect. To check it, optimization should be performed using the linear programming method, which is a universal tool for solving this type of problems [11].

\section{Conclusion}

The main goal of the article was to present the possibility of using the simulation experiment and optimization in the production process. The presented example shows how a discrete events simulation model can improve a manufacturing plant design. The model 
was an integral part of the production line design process. It was used as a decision support system to help designers quickly evaluate the performance of various alternative manufacturing configurations and resource allocation.

FlexSim software with built-in OptQuest optimizer was used for the experiments. FlexSim uses a database management system that allows the user to build a simulation model in a way that is very similar, if not identical, to the one in which he would build a production database. The user is relieved of all modeling work and can concentrate on describing the system and then analyzing the simulation results. Before running the simulation, FlexSim will verify the user's description for consistency and completeness, and the relational database will automatically discard incomplete and inconsistent data.

One of the analyses was carried out as part of the project to study the sensitivity of the number of employees hired to different levels of variability. The analysis of the scenario study for different numbers of employees clearly showed a significant impact on the system throughput and cycle time. Research has shown that production time will decrease to a certain level as the number of employees increases. Further employment growth will no longer reduce production times.

The model proved to be an effective design and planning tool. The concept presented in the paper may be the basis for constructing more complex simulations. It is worth pointing out that the simulation model and the optimizer work independently, despite being integrated in one package. The logic of the model should be consistent with the real working system, but the optimizer often requires more variables to work properly. A correctly built simulation model can be used many times, for example to change the production structure in the event of a market reversal.

\section{References}

[1] INGALDI, M., DZIUBA, S.T., CIERNIAKEMERYCH, A. (2018). Analysis of problems during implementation of Lean Manufacturing elements. In: MATEC Web Conf., Vol. 183, pp. 1004.

[2] KNOP, K. (2019). Evaluation of quality of services provided by transport \& logistics operator from pharmaceutical industry for improvement purposes. In: Transportation Research Procedia, Vol. 40, 1080 - 1087.

[3] TRAN, T.A., LUU-NHAN, K., GHABOUR, R., DAROCZI, M. (2020). The use of Lean SixSigma tools in the improvement of a manufacturing company - case study. In: Production Engineering Archives, Vol. 26, No. 1, pp. 30 - 35.
[4] KLIMECKA-TATAR, D. (2018). Context of production engineering in management model of Value Stream Flow according to manufacturing industry. In: Production Engineering Archives, Vol. 21, No. 1, pp. $32-35$.

[5] KLIMECKA-TATAR, D., INGALDI, M. (2020). Assessment of the Technological Position of a Selected Enterprise in the Metallurgical Industry. In: Materials Research Proceedings, Vol. 17, pp. $72-78$.

[6] ULEWICZ, R., JELONEK, D., MAZUR, M. (2016). Implementation of Logic Flow in Planning and Production Control. In: Management and Production Engineering Review, Vol. 7, No. 1, pp. $89-94$.

[7] ULEWICZ, R., KUCĘBA, R. (2016). Identification of problems of implementation of Lean concept in the SME sector. In: Ekonomia $i$ Zarzadzanie, Vol.8, No. 1, pp. 19 - 25.

[8] MAZUR, M., MOMENI, H. (2019). LEAN Production issues in the organization of the company - results. In: Production Engineering Archives, Vol. 22, pp. $50-53$.

[9] KRYNKE, M. (2020). Risk Management in the Process of Personnel Allocation to Jobs. In: $8 t h$ International Conference System Safety: Human Technical Facility - Environment (C₹OTO 2019), pp. $82-90$.

[10] INGALDI, M. (2020). A new approach to quality management: conceptual matrix of service attributes. In: Polish Journal of Management Studies, Vol. 22, No. 2, pp. 187 - 200.

[11] KRYNKE, M., MIELCZAREK, K. (2018). Applications of linear programming to optimize the cost-benefit criterion in production processes. In: MATEC Web Conf., Vol. 183, pp. 4004.

[12] KRYNKE, M., MIELCZAREK, K., VAŠKO, A. (2019). Analysis of the Problem of Staff Allocation to Work Stations. In: Quality Production Improvement-QPI, Vol. 1, No. 1, pp. 545 - 550.

[13] KYNCL, J., KELLNER, T., KUBIŠ, R. (2017). Tricanter Production Process Optimization by Digital Factory Simulation Tools. In: Manufacturing Technology, Vol. 17, No. 1, pp. 49 - 53.

[14] ULEWICZ, R. (2014). Practical Application of Quality Tools in the Cast Iron Foundry. In: $M a-$ nufacturing Technology, Vol. 14, No. 1, pp. 104 111.

[15] ZHUANG, C., LIU, J., XIONG, H. (2018). Digital twin-based smart production management 
and control framework for the complex product assembly shop-floor. In: Journal of Advanced Manufacturing Technology, Vol. 96, pp. 1149 1163.

[16] SETAMANIT, S. (2018). Evaluation of outsourcing transportation contract using simulation and design of experiment. In: Polish Journal Of Management Studies, Vol. 18, No. 2, pp. 300 310.

[17] GARRIDO, J.M. (2009). Object Oriented Simulation: A Modeling and Programming Perspective, pp. 490, Springer US, Dordrecht.

[18] SUJOVÁ, E., VYSLOUŽILOVÁ, D., ČIERNA, H., BAMBURA, R. (2020). Simulation Models of Production Plants as a Tool for Implementation of the Digital Twin Concept into Production. In: Manufacturing Technology,Vol. 20, No. 4, pp. $527-533$.

[19] BECKER, W.D., ECKHARDT, J., FRECH, R.W. (1998). Modeling, simulation, and measurement of mid-frequency simultaneous switching noise in computer systems. IEEE Transactions on Components, Packaging, and Manufacturing Technology: Part B, Vol. 21, No. 2, pp. 157 - 163.

[20] DRBÚL, M., STANČEKOVÁ, D., BABÍK, O., HOLUBJAK, J., GÖRÖGOVÁ, I., VARGA, D. (2016). Simulation Possibilities of 3D Measuring in Progressive Control of Production. In: Manufacturing Technology Vol. 16, No. 1, pp. $53-58$.

[21] SUJOVÁ, E., STŘIHAVKOVÁ, E., ČIERNA, H. (2018). An Analysis of the Assembly Line Modernization by Using Simulation Software. In: Manufacturing Technology, Vol. 18, No. 5, pp. $839-845$.

[22] LE, T.D.C., NGUYEN, D.D., OLÁH, J., PAKURÁR, M. (2020). Optimal vehicle route schedules in picking up and delivering cargo containers considering time windows in logistics distribution networks: A case study. In: Production Engineering Archives, Vol. 26, No. 4, pp. $174-184$

[23] SETAMANIT, S. (2019). Improving transportation contract management using simulation. In: Polish Journal Of Management Studies, Vol. 20, No. 2, pp. $466-477$.
[24] GARRIDO, J.M. (2009). Introduction to Flexsim, In: Garrido, J.M. (Ed.), Object Oriented Simulation. A Modeling and Programming Perspective, pp. 31 - 42, Springer US, Dordrecht.

[25] BEAVERSTOCK, M., GREENWOOD, A., NORDGREN, W. (2017). Applied Simulation Modeling and Analysis Using FlexSim, 5th edn., FlexSim Software Products, Inc.

[26] LEKS, D., GWIAZDA, A. (2015). Application of FlexSim for modelling and simulation of the production process. In: Selected Engineering Problems, Vol. 6, pp. 51 - 56.

[27] KACZMAR, I. (2015). Cost optimization of blend preparation with the use of the flexsim environment. In: Agricultural Engineering, Vol. 4, No. 156, pp. $51-60$.

[28] KACZMAR, I. (2016). The use of simulation and optimization in managing the manufacturing process - case study. In: Gospodarka Materiatowa i Logistyka, Vol. (4), pp. 21 - 28.

[29] KRENCZYK, D., KEMPA, W.M., KALINOWSKI, K., GRABOWIK, C., PAPROCKA, I. (2017). Production planning and scheduling with material handling using modelling and simulation. In: MATEC Web Conf., Vol. 112, pp. 9015.

[30] GELENBE, E., GUENNOUNI, H. (1991). FLEXSIM: A flexible manufacturing system simulator. In: European Journal of Operational Research, Vol. 53, No. 2, 149 - 165.

[31] KACZMAR, I. (2019). Computer modeling and simulations of logistics processes in the flexsim environment, pp. 260, Wydawnictwo Naukowe PWN, Warszawa, (in Polish).

[32] FLEXSIM (2017). User manual.

[33] KNOP, K. (2020). Indicating and analysis the interrelation between terms - visual: management, control, inspection and testing. In: Production Engineering Archives, Vol. 26, No. 3, pp. $110-120$.

[34] KYNCL, J. (2016). Digital Factory Simulation Tools. In: Manufacturing Technology, Vol. 16, No. 2, pp. $371-375$. 